\title{
English Language for Refugees at Higher Education
}

\section{OPEN ACCESS}

Volume: 9

Special Issue: 2

Month: September

Year: 2021

E-ISSN: 2582-1334

Received: 09.07.2021

Accepted: 29.08.2021

Published: 15.09.2021

Citation:

FarukIpek, Omer. "English Language for Refugees at Higher Education." Shanlax International Journal of Education, vol. 9, no. S2, 2021, pp. 77-87.

DOI:

https://doi.org/10.34293/ education.v9iS2-Sep.4373

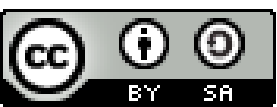

This work is licensed under a Creative Commons Attribution-ShareAlike 4.0 International License

\section{Omer Faruk Ipek}

Assistant Professor

Bolu Abant Izzet Baysal University, Turkey

D https://orcid.org/0000-0003-1921-3332

\begin{abstract}
After the massive immigration caused by the war in middle east, English language filled the communication gap between the people of host counties and refugees. Framing the study with language learning for resilience, in this qualitative case study, the status of refugee students at a Turkish higher education foreign language institution has been investigated to find out: (a) educational background of refugee students, (b)refugees' current state of language learning for resilience, and (c) instructors' positions on English education for resilience.Two Iraqi, one Syrian refugee students and their two language teachers participated in this study. Tocollect data, semi-structured interviews were conducted. The results showed us that although these students are coming from different educational backgrounds, they hold similar beliefs about English education and have hopes for their future. It is implied that with special and intensive assistance, being competent in English language will open the gates to global opportunities for refugees.
\end{abstract}

Keywords: Refugee education, Resilience, Migration.

\section{Introduction}

The war in Syria and Iraq caused depressing results in every part of life including education. Many people were forced to leave their homes and schools, and migrate to safer counties such as Jordan, Lebanon, Turkey and to the countries in Europe. According to the report that United Nations High Commissioner for Refugees (UNHCR, 2017) released, over 5 million people have had to abandon Syria since 2011. European Commission of Humanitarian Aid and Civil Protection (ECHO) (2016) report states that 3.1 million refugees are placed in Turkey since 2011. The recent publication of UNHRC (2021) claims that this number increased to 3,6 million (see figure 1). With the huge numbers of migration, social, security, health and educational needs emerged in Turkey. Furthermore, in Refugee Resilience Program Report (2018), it is stated that 1.06 million Syrian children are enrolled at formal education while 287,000 Syrian children are registered to the non-formal education. In the following table, the top five countries that host refugees after the war in Iraq and Syria are listed. According to the Figure 1 below, Turkey has by far the most crowded refugee population.

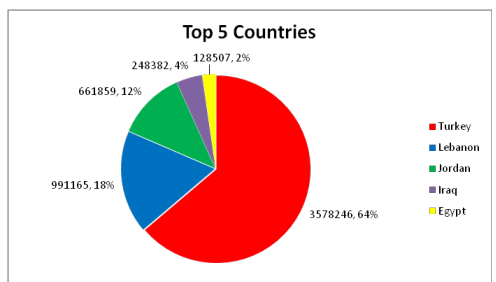

Figure 1: Top Refugee population in 5 countries (UNHCR report, 2017) 
In a report published by the Directorate of General Immigration Administration (DGIA, 2021) in Turkey, the change in the Syrian refugee numbers in Turkey is seen (figure 2). It is understood that while in 2012, there were about 14,000 Syrian refugees in Turkey, this number is now more than 3.5 million; therefore, it can be concluded that Turkey became the center of refugee movement and residence. Also, "Protection of Academic Heritage in the Middle East" report (2018) states that there are 976,200 Syrian school age children in Turkey. Among the total Syrian Refuges getting education, and according to the Higher Education Council (HEC) report (2017) in Turkey, there are 15,042 Syrian students studying at Turkish universities.

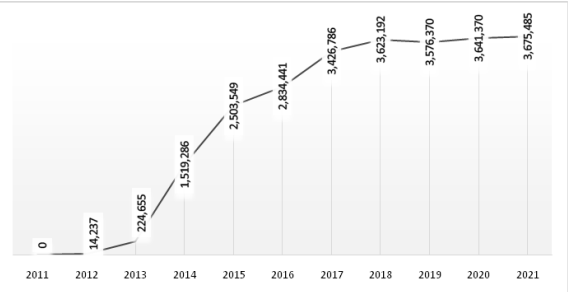

Figure 2: Syrian Refugees Under Protection in Turkey (DGIA, 2021)

It is understood that refugee education stands as a big matter for the host countries and their national education systems. Taylor and Sidhu (2012) stated that particular needs, lacks, and necessities of refugee education is ignored by the governments, districts, and even schools. However, in Refugee Resilience Program report (2018) it is stated that Turkey educated over 140,000 public school teachers for the refugees, which means that Turkey has done its best to prepare their system for the refugee education.

According to Rotter (2006), when refugee students are not given special interest regarding curriculum design or intercultural education, and they are treated in the homogenous groups, understanding their special needs, and developing suitable support would constraint their educational improvement. Icduydu (2015) also listed the reasons why refugee case requires special attention. It is summarized that there is now a bigger negative attitude towards the refugees by the host people although this was reverse at the beginning. Secondly, Turkey welcomes the refugees with a temporary protection program that turned into a permanent one which would affect the educational aspect of migration. Third, as the Syrian refuges started to migrate to Turkey, some of them do not stop and see Turkey as a transit station for their final destination which is Europe. Lastly, it is uttered that Turkey has undergone great changes in the migration and refugee crisis that requires a deep understanding. Isiguzel and Baldik (2019) analyzed the governmental language and general education policies on refugee education and integration to schooling in Europe and Turkey. For Turkey, they summarized that Turkish government first published several official documents in 2013, regulating the precautions towards the refugees that migrated to Turkey after the war. After this very first official document, the second came right after the first one in the same year emphasizing teacher employment, curriculum about refugee education, student registration into the Turkish schools, and Turkish language education. In 2014, another official document was released about refugee education in Turkey claiming the system of accreditation of refugees' previous education institutions which enabled refugee students to continue their education at universities in Turkey. In 2016, a very extensive project called 'Promoting Integration of Syrian Children into Turkish Education System (PICTES)' was launched with the European Commission in order to accomplish the integration of refugee students into the Turkish education. Then in 2017, a workshop was organized in order to determine the language proficiency exam for refugee education. Later, in 2018, the details for language proficiency for each skill was specified in an official document. It can be easily understood that Turkey has made great efforts in order to integrate refugee students into their new world and education.

As the education integration of refugees and school aged children is an issue for integration to the host culture, language is an important portion of the public life, and it is accepted as the vehicle to receive proper education (Council of Europe, 2003). The integration of refugees into their new environment also stands as a big issue for the countries. Learning a new language has an effect to improve one's global awareness skills and sets links between the host culture and the society (Contech, 2015). While 
there are numerous studies investigating the social and general educational needs of refugees, English language education has not taken enough attention. It is obvious that Language learning stands as a key instrument in refugee education to protect their hopes for future and to get appropriate global education. This belief formulated the scope of this study. Understanding the background and life experiences of refugee students and their objectives to learn English which is accepted as the common language globally is explored in this study.

\section{Studies on Refugee Education}

After the big and chaotic migration process from Syria and Iraq to Turkey, Turkish government via Ministry of National Education (MoNE) started educational regulations and implementations for the children in need (MoNe, 2014). By doing so, many researches have been conducted on Syrian children in K-12 education level. Taylor and Sidhu (2012) investigated the schooling effect of refugee education. Specifically, they studied multiple cases in four schools and their efforts to meet the needs of young people who come from refugee background. They found out that a holistic approach to education and welfare, leadership, inclusive education approach, support for learner needs, working with other agencies are necessary for the needs of good practice, targeted policies and system supports and commitment to social justice. In another study, Arnot and Pinson (2005) asserted that the policy of the curriculum rarely meets the specific needs of the refugee students. On the other hand, they found out that refugee students' needs can be grouped into three: learning, emotional and social. While they have needs in those categories, it is also stated that schools mostly deal with the learning needs on language. Similarly, in another study (Taylor, 2008), attention is given to students' language, social and emotional needs. Buckner et al. (2017) examined the refuge educational policy in Lebanon, and found out that in local contexts, the government's educational policies for refugees are not completely implemented. Moreover, in some areas, the local implementations have some contradictory operations. Karam et al. (2017) conducted a case study in three refugee settlements in Lebanon. They investigated the decision-making processes conducted by the teachers and managers regarding curriculum and language teaching and instruction. It is found out that some teachers especially the ones teaching English stated that they teach what they want while some said that they use the Lebanese language curriculum. It is also indicated that Lebanese curriculum used in that site tries to fulfill the requirements and the needs of Syrian refugees. Also, it is stated that the content of the courses would start to be given in the refugees' native language in order to overcome the comprehension difficulties.

In the Turkish context, Aydin and Kaya (2017) studied the status of Syrian refugee education in elementary schools in Turkey. They investigated the needs of Syrian refugee students' needs from teachers and school principals' perspectives. In their study, it is found out that Turkey enables these students a secure and welcoming school environment. On the other hand, it is stated that the teachers are not wellequipped and trained in order to instruct refugees. It is also asserted that there is an insufficiency in curriculum planning and resources. Also, Dorman (2014) did a case study in a Turkish context about the educational opportunities for the Syrians, questioned the quality of education provided, the educational barriers to participate in the classes, and psychological and educational needs of the refugees. It is concluded that more funding is required, Turkish schools need to accept more Syrian children, child labor and early marriage needs to be stopped by supporting them financially, and social activities need to be organized for community integration. The findings of these researches implied to investigate the English language education for refugee students as it is believed that their link to their new future can be established by the global language

\section{Conceptual Framework: Language for Resilience}

Van Breda (2018) defines resilience as "the multilevel processes that systems engage in to obtain better-than-expected outcomes in the face or wake of adversity" (p.4). As resilience literature has grown in the recent years due to the wars and immigration, the scope of it also has undergone several changes. Capstick (2018) argues that resilience now should be discussed as emotional and academic resilience. 
Also, Capstick and Delaney (2016) published a report named 'Language for Resilience' for refugee education in the host countries. The report investigates the benefits of language learning for refugees in the host countries regarding 'resilience'. The concept of language and resilience is explained that there are language barriers to the refugees and these barriers hinder to reach the education in their host countries. Also, Capstick (2018) claims that "to develop competence in additional languages can enable them to find a voice so that their stories can be told and understood, as well as providing access to a wider range of employment and training opportunities" (p.212).

The report summarized how language improves and enriches resilience and it is found out that there is a positive relationship between the language competence and their academic achievement at school. Therefore, it can be inferred that refugees' language competences need to be considered in detail. Secondly, it is stated that access and achievement in a new language would enhance their chances to find jobs and have hopes to find jobs in their future lives. Thirdly, it is claimed that language learning tasks and activities in the host classes and social cohesion enables individual resilience to the community. Also, the report points out that language learning would aid the refuges to overcome their psychological traumas and depressions during the process of language learning. Lastly, it is stated that this whole process would help the policy makers, program designers and the teachers to build and strengthen their educational programs.

These five items for language resilience frame our study. By looking at the language for resilience framework, it is aimed to investigate the new language learning process that refugees undergo in the host community, and the answers to the following research questions are explored.

1. How do refugees explain their journey to Turkey and their previous education?

2. What are their thoughts about English language education and their provisions for the future?

3. How do language instructors explain their refugee students' current state?

\section{Method \\ Research Design}

Both qualitative and quantitative research seek to reveal the beliefs and thoughts of the participants; however, participants' point of view is investigated more in the qualitative research design (Denzin\& Lincoln, 2011). Therefore, in order for a better understanding of the case, this study is designed as a qualitative research (Creswell, 2009). This specific case followed the procedures of descriptive case study model explained by Yin (2009) in order to comprehend and describe the individuals' explanations of the phenomena and the special case.

\section{Research Sample}

In the case of this study, there are three students who started their university education having enrolled at Turkish Language Center and studied Turkish language there for one year, and then registered to English Preparatory department. It can be said that those three students are the first refugee students that the English Preparatory department have. However, it is obvious that by the growing population Syrian and Iraqi refugees, the number will rise gradually in the following years. The other participants are two English language instructors of refugee students.

\section{Context}

The study is conveyed in an English language teaching institution at a Turkish public university. The university is more than 25 years old and has more than 30,000 students. The school's main aim is to teach English to the new university students for one academic year in two semesters. One semester lasts for 15 weeks, so students get 30 weeks of English language education. In a week, they are taught 24 hours of English that makes 720 hours of intensive language education. The language institution where this study is conveyed mostly consist of Turkish students and instructors, so refugee students are new to everyone in the school.

\section{Data Collection}

Semi-structured interviews with the refugee students were used as the data collection tool. Openended questions were asked to both parties. After the pilot study, for students, 19 questions, and for 
the instructors, 11 questions were decided. The interviews lasted for nearly two hours for students and one hour for the instructors. The interviews were audio recorded and verbatim transcription is done. The interviews were conducted in the participants own language which means that for student interviews, two Arabic translators were involved in the research. They were given the questions for giving them enough time to be prepared, and then after they agreed on the translated sentences, interviews started.

\section{Data Analysis}

The data is analyzed through Creswell's (2013) qualitative data analysis procedures. In this type of data analysis, researchers first prepare and organize the data. In this study, after the verbatim transcriptions, nearly 70 pages of data were prepared, and they were organized under each research question. The second step is reducing the data. In this step, unnecessary and irrelevant information is omitted. The last step is to present the findings in figures or in discussion. Here, an in-depth discussion has been made in the end.

\section{Findings}

\section{Education Background and Journey to Turkey}

Fatma is from Syria, and she immigrated to Turkey in 2012 because of the war in her home country. She first went to Jordan with her family; however, she states that because of the living conditions, her family decided to move to Turkey. She points out that she was always good with English in her past education - she enjoyed the lessons and participated actively to the lessons when she was in Syria. She says that she had always wanted to study Pharmacy and intended to become a pharmacist in her future career.

Ali, our second participant, is from Kerkuk, Iraq. When he was one year old, he moved to Libya with his family, and he went to school there until he started university. After the internal war had started in Libya, he had to migrate to Turkey. He went to a private high school in Libya, and he states that education was outstanding there. He says that teachers were mostly coming from other cities, and they were having one hour English lesson every day in a week. He also claims that he was good in English, especially in listening and reading skills. He applied to the Turkish university with his scores that he took in Libya, and he enrolled in Biology department at university.

Osman, the third participant, pointed out that after life had become unbearable in Iraq, he first immigrated to Jordan with his family. He stayed there for six years; however, his family decided to move to Turkey as they thought the life and educational conditions were much better in Turkey. He added that he went to Jordan like a home-citizen, and he reports that they were not like immigrants in Jordan as they stayed at a house, not at a refugee camp. He adds that there were only Syrians in the camps in Jordan, and he states that he was lucky to stay in a house. He studied in Iraq until the 6th grade, and he continued his education in Jordan till the 12th grade. He finished and took the high school diploma in Turkey. He remarked that he used to be an outperforming student in Iraq and Jordan and his average score in the school was over 90 out of 100 . He also adds that they used to get a very good English language education and they were taught English after grade 5 in Iraq. English was taught to them every day for one hour. He says that his dream was to become pilot when he was in Iraq.

\section{Current State: Learning English Language for Resilience}

After the analysis of the interview results, the first theme emerged is communication. Although Fatma's first weeks at the English preparatory department were a bit difficult due to language problems, she sates that this problem was minimum at the end of the year. She explains this as "learning English closed the communication gap between me and my teacher and my classmates". She points out that at the very beginning of the year, she could only talk to her other refugee friends in the class as it made her more comfortable and safer during the class hours. However, after some time as language levels increase, she had the opportunity to set communication with the home students in the classroom. She adds that, their communication was not only limited into the classroom, but her classmates also started to call her out during the breaks and after lessons. In terms of 
her relations with her teachers, she points out that from the very first beginning, her teachers were aware of their existence in the class although they did not talk to them directly about their background. She adds that she could understand her teachers' efforts to make them more active in the class time by posing questions more than home students, having them be partners with Turkish students during the class activities, and putting them into different groups rather than letting them be groups with refugee students for the discussion activities. Fatma also explained her semester after she passed on her major program. She says that the class atmosphere is not as friendly and interactive as in her major program. She explains that they have direct interaction with the students in the classes neither with her classmates nor the lecturer. She also continues that this may be because of the nature of lecturing in the faculties; however, she emphasized that she missed the class atmosphere in English preparatory department.

Ali points out the difference between his first weeks and last weeks in the class regarding interaction as a very huge difference. He points out that, as home students in the class did not know Arabic, which is his native language, and he does not know Turkish, Turkish and refugee students were not able to have any communication with each other. However, he noted that after time passed and due to the increase in English language level and pair and group works with the home students, he started to set communication with the members of the class. On the other hand, he also mentions that while they were having communication with Turkish students in the class, sometimes Turkish students were stuck in conveying their message in English, and they suddenly stopped the communication.

Osman stated that from the beginning of the classes, he felt lonely because of having no communication with his classmates, and that caused a bit of disappointment for him regarding racism. However, after weeks, he felt regretful of such thought as he realized that the non-communication was not because of racism, but because of the lack of appropriate language for communication. He emphasized that after their language level improved, home students wanted to talk to him about his daily lives, and he became much more motivated to attend and participate in the classes.

The second theme for students' current English language education is curriculum. They explained the language curriculum that they were taught in detail. Ali started explaining from the registration process. He stated that he was registered to the department on the internet. After he was accepted, he took the language proficiency exam which he thinks was not that much difficult. After the department had announced the exam results, he was placed in B level where students with an elementary level English knowledge were placed. In B levels, there were no beginner level students. He stated that there were only two B level classes consisting of 25 students in each, while there were over 20 A level groups. He points out that this is a success of his previous English education and the placement exam.

Ali also stated that he was a bit weak in writing skills while he finds himself successful in listening, speaking, grammar and vocabulary. He also claimed that he benefitted more from group work. He stated that vocabulary had been taught in group work and he loved it. He claimed that they lack pair and group work in their home countries as the class size was much bigger than their class in Turkey. He continued the positive sides of the curriculum that he was happy with the native English language teachers. He pointed out that native language teachers forced them to speak English. He also stated that class atmosphere was convenient for them to learn English, and books which they use were quite effective. The only thing that he criticized was the lack of departmental terminology. He claimed that they were only taught general English but no academic vocabulary.

Osman took the English placement test at the beginning of the semester, and he thinks that it was a rather difficult exam. He thinks that the exam was a bit different from the education that he took in his home country. He stated that he is good in speaking and reading skills. He claimed that although his teachers had a huge effort, he always had difficulty in writing and listening, but he adds that it is his personal problem. He agrees Ali that books were effective in teaching English. 
Future Hopes: Learning English Language for Resilience

Fatma's dreams were damaged by the war in her country. When Fatmawas asked her current department, she stated that she is now studying Chemistry in Turkey. She explains her choice for her current major as follows:

The university in my current city does not have a pharmacy program, but the most similar program that accepts students like me is chemistry department. By studying at chemistry department, in which the medium of education is English, I plan to work in the big pharmacy sector in Turkey in my future.

Ali states that, in his home country, he was neutral to learning English. He used to see English as an ordinary subject like the other subjects in his school. However, he adds that he recognized the importance of learning English when he started university in Turkey. He explains it as follows:

I was dreaming to become a physicist when I was a kid, and that is why I chose Physics program in this university. When I didsome research about the department in this university, I saw that the medium of education was English, and I needed to learn English. I was happy to start learning English as I believed it would aid my academic skills and communication skills with the people in Turkey

It is clear from their words that although they have suffered from two devastating wars, they still did not lose hope and they try to plan their future. To do so, they have not given up their dreams that they have in their home countries, and they strive for becoming a physicist and a pharmacist. Ali also shared his feeling about his current state. He claimed that he is now 24 years old, and he was expected to graduate from university until now: however, he claims that he is still in the first year of the university education and this upsets him. He thinks that he lost a lot of time. He adds that he is in the same class with younger students and that demotivates him. He also adds that his plan is to finish university and then try to find a good job in Turkey. Moreover, he plans to go to a different county if he finds a better job there.
Fatmaon the other hand is a little discouraged about the future that she thinks the only hope for future is the education that she received in her university in Turkey. She states that she wants to continue her English education unless there is an obstacle. When she was asked about her discouragement about the future, she mentioned her previous experiences during her education in the past: however, she also stated her positive feelings about her future. It is claimed that if she succeeds to get a diploma from a Turkish university, she will feel luckier than her friends living in other Middle Eastern countries.

Osman also shared his feelings about his future. He states that many things disappear in his life after such a long journey in a very short period. He states that it was so dreadful to be far from the family, his people and his country. He also adds that his future is ambiguous, he does not know what to do after university even if he completes his department. He claims that if he had the chance to go back to his home country, he would not stay in Turkey, but he says it seems quite impossible under these circumstances.

\section{Instructors position on English Language Teaching to Refugees}

Three instructors taught in the class where the refugee students were getting English language education. Two of them were Turkish and one of them was American. We only had the chance to interview with the Turkish teachers. These teachers are both under 30 years old, one male (Mehmet) and the other is female (Ece) and have five to ten years of teaching experience.

Ece states that she had not been informed about the refugee students before courses started and she adds that it was not a problem for her; however, it would have been better if she had known in advance. She claims that she did not do any special preparation before the class, but she did some changes during the class time. She points out that previously, shesometimes had to switch her language to Turkish, but as there were refugee students in the class, she could not do that. The positive side of having refugee students in the class is stated by Ecethat all students in the class felt that they had to speak English due to having refugee students in the class as their Turkish language knowledge was so little. She shared her 
experience that once she found her Turkish students trying to explain the subject to refugee students in English which she had never seen before. Ece also mentioned that refugee students were so motivated, and they had no hesitation about posing questions which means they were slightly active. She adds that while she was monitoring the students, she realized that they were always doing the activities. Moreover, she shared one of her memories as follows:

These refugee students were aware that they needed English. Once I asked them what motives them and they said that they would most probably live in Turkey, so they needed to learn it. These students were aware of the importance of English in their future lives.

She also explained these students' learning styles. She said that they were note-taking while she was lecturing. Also, those students were in the same group, so they always helped each other especially with the vocabulary. She also expressed that if these students did not understand the topic, she would feel awful as she felt herself more responsible for teaching refugees than teaching Turkish students.

Mehmet also had not known that he had refugee students in his class in advance. He thought that having these students in the class would aid the instructional process. He stated that he had positive discrimination towards refugees. Mehmet explains his attitudes as follows:

Even if Turkish students come from different cities in Turkey, they have similar or same educational or cultural backgrounds. They passed through the same educational process. Since refugee students came from a different education background, they may demonstrate and apply different learning techniques in the classroom. I was aware of that.

He also claimed that if refugee students asked something that they did not understand, he would shape and change his own teaching technique according to them. Similar to Ece, Mehmet stated that he could never use his mother tongue in the class; therefore, he used to make preparation before the class time accordingly and he always planned his lesson for refugee students. He points out that these students did not use to be partners or be in the same group with Turkish students which Ece also mentioned. On the other hand, he states that these students used to talk to Turkish students after the lesson or during the breaks. Lastly, Mehmet stated that he was quite cautious about the course content. He skipped the texts about war or immigration that he did not want his students' motivation decrease.

\section{Discussion}

The literature on refugee education has started to grow as countries like Lebanon, Jordan, Egypt and Turkey wanted to help the needs of refugee families and school age children and such countries made several official regulations in their own system. For example, PIKTES aimed to help refugee children regarding their educational needs that is under the protection of Ministry of National Education (MoNE) in Turkey (Ekin\&Yetkin, 2021). Similarly, in this study, it is seen that, Turkey provided refugee students special opportunity to continue their university education. Also, Taylor and Sidhu (2012) stated that there needs to be positive attitudes towards refugee students in the whole school, and this should be supported by school leaders and education authorities. It is clear in this study that teachers of these students tried to create a welcoming and friendly environment in the class. Also, according to the refugee students in this study, their classmates was a great help to them as they were trying to speak to them after the lessons, and they were helping to the refugee students with the new subjects in the class. This situation is also mentioned in Rotter (2006) as it is stated that good practice of refugee education relies mostly on three areas: a welcoming environment, free of racism, and social psychological needs. In another study, Arnot and Pinson (2005) stated that refugee students may have multiple needs and the institutions or governments should meet these needs. According to the reports stated in this study, Turkish government have spent a lot of time and money on wellbeing and educational needs of refugees coming to Turkey.

Also, as we can see in the interview results, it is said that refugee students did not use to contact with Turkish students at first which gradually changed after some time that they spent together in the same class. It is pointed out in Isiguzel and Baldik (2019) that the best practice of refugee education is 
to integrate them with the home students in order to create the language for resilience. Similarly, it is stated in Hamilton (2004) and Roy and Roxas (2011) that social skills and integration to the target culture are problematic issues for the refugee education which needs intervention during schooling. Teacher capacity for refugee education has been mentioned in the language for resilience framework which is also an issue in this study. The teachers stated that they were not informed about the refugee students and the institution had not been prepared for them. This result routes us to the findings of Kiremit et al (2018) and Kardes and Akman. (2018) that there are teacher competence and teacher adaptation problems. Miller et.al. (2018) summarized the resilience of refugee student that these students have distinguished abilities that they demonstrate independent learning skills during their schooling. It is also stated that schools need to cope with and make appropriate adjustments in their implementations and pedagogy highlight and support refugee students' academic and social wellbeing. Capstick and Delaney (2016) listed the key findings in 'Language for Resilience' report as follows:

- Every language used by the refugees helps them to build resilience at the individual family and community levels. Both home and their additional languages matter,

- Proficiency in additional languages provides new opportunities for education and employment.

- Proficiency in key languages gives people a voice to tell their story in various contexts.

- Language in additional languages provides new opportunities for education and employment,

- Language learning can bolster social cohesions and intercultural understanding,

- Language learning activities can be supportive interventions to address the effects of loss, displacement and trauma,

- Building the capacity of language teachers can strengthen the resilience of the formal and nonformal systems in host communities (p.5).

When we look at the above-mentioned findings of resilience report, the items go parallel with the findings of the current study. According to all the participants' interview results, they stated how they see English language education as a new opportunity for their future which goes parallel with the findings in the report. Also, Matthew (2008) claimed that delivery to language literacy is profoundly urgent for refugees' future options, social integration and after-school lives. Additionally, it is pointed out in Hutchinson and Kettlewell (2015) that the improvement in academic and language improvement, and assistance for professional lives would establish better capabilities and potential in refugees' hopes and lives. It is also argued in Basar et al (2018) and Cho et.al. (2019) that refugee English language learners have a strong desire to be competent in English and teachers see their increasing behaviors to learn it.

The findings reveal that refugee students have a prejudice before getting inside the classroom, and it took some time to for them to accustom their own position in the classroom. It is understood that these students sticked to each other during the class time at first: however, after the natural adjustment period, they started to communicate with their classmates. So, it can be concluded that time should be given to refugee students to get accustomed to their new environment. It is also understood that refugee students in our context have a background of English language education in their previous schools. Therefore, it can be concluded that these students hold certain beliefs about language learning.

\section{Conclusion}

It can also be concluded that refugee students, like the other host students, have dreams and hopes for the future and English language plays a massive role in actualizing their dreams. Therefore, both policy makers and educators need to be aware of this fact and make regulations accordingly. Although institutions like MoNE in host countries give preservice education and educate their staff for the refugee education, similar implementations should be conducted at university level as the instructors in this study revealed that they had not been informed about the refugee students in their classroom. To help them, instructors may interview with these students before the semester starts and reveal their language learning beliefs. By informing and providing them intensive training, teachers would have the chance to arrange their teaching according to the needs of their refugee students. 
References

Arnot, Madeleine, and Halleli Pinson. The Education of Asylum-Seeker and Refugee Children: A Study of LEA and School Values, Policies and Practices. University of Cambridge, 2005.

Akademik Mirason Seyir Defteri. Higher Education Council (HEC), 2021.

Aydin, Hasan, and Yeliz Kaya. "Education for Syrian Refugees: The New Global Issue Facing Teachers and Principals in Turkey." Educational Studies, vol. 55, no. 1, 2019, pp. 46-71.

Başar, Murat, et al. "Learning-Teaching Process Issues in Classrooms with Refugee Students." Kastamonu Education Journal, vol. 26, no. 5, 2018.

Buckner, Elizabeth, et al. "Between Policy and Practice: The Education of Syrian Refugees in Lebanon.” Journal of Refugee Studies, vol. 31, no. 4, 2018, pp. 444-465.

Capstick, Tony. "Resilience.” ELT Journal, vol. 72, no. 2, 2018, pp. 210-213.

Capstick, Tony, and Marie Delaney. Language for Resilience: The Role of Language in Enhancing the Resilience of Syrian Refugees and Host Communities. British Council, 2016.

Cho, Hyonsuk, et al. "Social-Emotional Learning of Refugee English Language Learners in Early Elementary Grades: Teachers' Perspectives." Journal of Research in Childhood Education, vol. 33, no. 1, 2019, pp. 40-55.

Conteh, Jean. The EAL Teaching Book: Promoting Success for Multilingual Learners. Sage, 2015.

Guide for the Development of Language Education Policies in Europe: From Linguistic Diversity to Plurilingual Education. Council of Europe, 2003.

Creswell, John W. Research Design: Qualitative, Quantitative, and Mixed Methods Approaches. Sage, 2009.

Creswell, John W. Research Design: Qualitative, Quantitative, and Mixed Methods Approaches. Sage, 2013.

Denzin, Norman K., and Yvonna S. Lincoln. The Sage Handbook of Qualitative Research. Sage, 2011.
Dorman, Stephanie. Educational Needs Assessment for Urban Syrian Refugees in Turkey. YUVA Association Press, 2014.

Ekin, Semih, and Ramazan Yetkin. "Teachers' Attitudes to Syrian Refugee Students in Turkey." Eurasian Journal of Applied Linguistics, vol. 7, no. 1, 2021, pp. 383-396.

Ferris, Elizabeth G., and Kemal Kirisci. The Consequences of Chaos: Syria's Humanitarian Crisis and the Failure to Protect. Brookings Institution Press, 2016.

Hamilton, Richard. "Schools, Teachers and Education of Refugee Children." Educational Interventions for Refugee Children: Theoretical Perspectives and Implementing Best Practice, edited by R. Hamilton and D. Moore, Routledge, 2004.

Hutchinson, Jo, and Kelly Kettlewell. "Education to Employment: Complicated Transitions in a Changing World." Educational Research, vol. 57, no. 2, 2015, pp. 113-120.

İçduygu, Ahmet. Syrian Refugees in Turkey: The Long Road Ahead. Migration Policy Institute, 2015.

Isigüzel, Bahar, and Yuksel Baldık. "Investigation of Education and Language Policies for Immigration Communities in Educational Systems." Nevşehir Hacı Bektaş Veli Üniversitesi SBE Dergisi, vol. 9, no. 2, 2019, pp. 487-503.

Karam, Fares J., et al. "The Students do not Know why they are here': Education DecisionMaking for Syrian Refugees." Globalisation, Societies and Education, vol. 15, no. 4, 2017, pp. 448-463.

Kardeş, Servet, and Berrin Akman. "Teachers' Views on the Education of Syrian Refugees." Elementary Education Online, vol. 17, no. 3, 2018.

Kiremit, Rahime Filiz, et al. "Teachers' Views about Syrian Students' Adaptation to School." Kastamonu Education Journal, vol. 26, no. 6, 2018.

Matthews, Julie. "Schooling and Settlement: Refugee Education in Australia." International Studies in Sociology of Education, vol. 18, no. 1, 2008, pp. 31-45. 
Yabancllara Yönelik Eğitim Öğretim Hizmetleri. Milli Eğitim Bakanlığ

Miller, Emily, et al. “Australian School Practices and the Education Experiences of Students with a Refugee Background: A Review of the Literature." International Journal of Inclusive Education, vol. 22, no. 4, 2018, pp. 339-359.

Roy, Laura A., and Kevin Roxas. "Whose Deficit is This Anyhow? Exploring Counter-stories of Somali Bantu Refugees' Experiences in Doing School." Harvard Educational Review, vol. 81, no. 3, 2011, pp. 521-542.

Syria Crisis. European Commission of Humanitarian Aid and Civil Protection, 2016.

Syrian Refugees Under Protection in Turkey Report. Directorate of General Immigration Administration (DGIA), 2021.

Taylor, Sandra. "Schooling and the Settlement of Refugee Young People in Queensland: ... the Challenges are Massive." Social Alternatives, vol. 27, no. 3, 2008, pp. 58-65.

Taylor, Sandra, and Ravinder Kaur Sidhu. "Supporting Refugee Students in Schools: What Constitutes Inclusive Education?" International Journal of Inclusive Education, vol. 16, no. 1, 2012, pp. 39-56.

United Nations High Commissioner for Refugees Report - 2017. UNHCR - The UN Refugee Agency.

United Nations High Commissioner for Refugees Report - 2021. UNHCR - The UN Refugee Agency.

Van Breda, Adrian. "A Critical Review of Resilience Theory and its Relevance for Social Work." Social Work, vol. 54, no. 1, 2018.

Yin, Robert K. Case Study Research: Design and Methods. Sage, 2009.

2016-2017 Öğretim Yllı Yükseköğretim Istatistikleri. Yüksekoğretim Kurulu, 2017.

Author Details:

Omer Faruk Ipek, Bolu Abant Izzet Baysal University, Turkey, Email ID: theipekk@gmail.com 